\title{
Butyrate Switches the Pattern of Chemokine Secretion by Intestinal Epithelial Cells through Histone Acetylation
}

\author{
Robert D. Fusunyan,, ${ }^{1,2}$ Jessica J. Quinn, ${ }^{1,2}$ Mika Fujimoto, ${ }^{1,2}$ \\ Richard P. MacDermott, ${ }^{2}$ and Ian R. Sanderson ${ }^{1}$ \\ ${ }^{1}$ Developmental Gastroenterology Laboratory, Harvard Clinical \\ Nutrition Research Center, Massachusetts General Hospital, Boston, \\ Massachusetts, U.S.A. \\ ${ }^{2}$ Gastrointestinal Section, Lahey Hitchcock Clinic, Burlington, \\ Massachusetts, U.S.A.
}

\begin{abstract}
Background: Butyrate, a fermentation product of intestinal bacteria, modifies chromatin structure through histone acetylation, thereby altering gene transcription. IL- 8 and MCP-1 are chemokines, expressed by intestinal epithelial cells, which attract neutrophils and monocytes, respectively. We hypothesized that butyrate may alter IL-8 and MCP- 1 expression by intestinal epithelial cells through histone acetylation.

Materials and Methods: $\mathrm{IL}-8$ and MCP-1 expression was measured by ELISA and RNA transfer blots. Acetylated histones were separated on acetic acid-urea-triton gels. Butyrate was compared to Trichostatin-A, a specific inhibitor of histone deacetylase and to other short chain fatty acids.
\end{abstract}

Results: Caco- 2 cells constitutively secreted MCP-1 but not IL-8. Butyrate reversibly decreased MCP-1 secretion. In contrast, butyrate increased $\amalg-8$ production. The effects of butyrate and Trichostatin-A were greater when cells were stimulated with $\mathbb{I L}-1 \beta$. Butyrate and Trichostatin-A both increased histone acetylation. Trichostatin-A and other short chain fatty acids altered chemokine secretion according to their effect on histone acetylation.

Conclusions: Butyrate reversibly switches chemokine secretion by epithelial cells through histone acetylation. We speculate that butyrate carries information from resident bacteria to epithelial cells. Epithelial cells transduce this signal through histone acetylation, modulating the secretion of chemokines.

\section{Introduction}

The small intestinal epithelium regulates the absorption of nutrients and also serves as a barrier to the external environment (1). Epithelial cells may also participate actively in host defense mechanisms (2). They express class II major histocompatibility complex (MHC) molecules and

Address correspondence and reprint requests to: Professor Ian R. Sanderson, Department of Paediatric Gastroenterology, St. Bartholomew's \& The Royal London School of Medicine \& Dentistry, Suite 42, Dominion House, 59 Bartholomew Close, London, EC1A 7BE, U.K. Phone: 171601 8589; Fax: 171600 5901; E-mail:

i.r.sanderson@mds.qmw.ac.uk they secrete chemokines in response to invasive pathogens $(3,4)$. The location of the intestinal epithelium between the luminal environment containing bacterial products and the immunocytes of the mucosal lamina propria puts it in a strategic position to respond quickly to changes in the external environment to maintain host equilibrium.

Luminal short-chain fatty acids, such as acetate, propionate, and butyrate, are the principal products of bacterial fermentation of ingested carbohydrates (5) in the gastrointestinal tract. The concentrations of short-chain fatty acids 
largely depend on dietary intake and on the types of bacteria present (6). Short-chain fatty acids are not present in the intestinal lumen before birth, but reach adult levels by the age of 1 year (7). Among the short-chain fatty acids, butyrate is the principal source of energy for colonocytes. Butyrate also has a stimulatory effect on epithelial cell proliferation in vivo (8), which contributes to epithelial cell restitution and integrity. Butyrate concentrations are higher in the large intestine $(5-24 \mathrm{mM})(5,9)$ than in the small intestine. However, concentrations of butyrate in the intestine increase significantly with bacterial overgrowth, as seen in short bowel syndrome and stagnant loops (10). Butyrate concentration is also increased in intestinal inflammation as seen in infants with necrotizing enterocolitis (11) and in patients with Crohn's disease (9). Because short-chain fatty acid concentrations reflect bacterial colonization, they may alter the secretion of cytokines that control inflammation. Intestinal epithelial cells synthesize and secrete a number of chemokines, including interleukin-8 (IL-8) (3) and monocyte chemoattractant protein-1 (MCP-1) (12). IL-8 and MCP-1 are two potent members of a family of at least 30 distinct 8-14 kD chemokines. Their genes are located at chromosomes 4 and 17, respectively. IL-8 has chemotactic and activating properties for neutrophils. MCP-1 attracts and activates monocytes. We have shown that butyrate enhances the secretion of IL- 8 by intestinal epithelial (Caco-2) cells stimulated with IL- $1 \beta$ (13). Its action on MCP-1 secretion has not been reported.

Changes in histone acetylation affect gene transcription by altering the charge on histones such that nucleosomes become less compact (14-16). Butyrate inhibits histone deacetylase activity, resulting in the increased acetylation of histones. The consequent destabilization on certain genes has been examined using DNase I sensitivity of defined regions of chromatin $(17,18)$. We hypothesized, therefore, that shortchain fatty acids regulate IL-8 and MCP-1 expression and that this regulation involves histone acetylation.

\section{Materials and Methods}

Culture of Intestinal Epithelial (Caco-2) Cell Monolayers

Caco-2 cells are epithelial cells derived from human colon carcinoma which differentiate in vitro after reaching confluence (19). Caco-2 cells (American Type Culture Collection, Rockville, $M D$, passages 20-40) were plated into 12-well plates (Falcon, Becton Dickinson, Franklin Lakes, NJ) at an initial density of $5 \times 10^{4}$ cells/ $\mathrm{cm}^{2}$. Caco-2 cells were grown in Dulbecco's modified Eagle medium (DMEM) (Gibco-BRL, Gaithersburg, $\mathrm{MD}$ ) containing $10 \%$ fetal bovine serum (FBS) (Hyclone Laboratories, Logan, UT), $2 \mathrm{mM}$ glutamine (Gibco), 100,000 U/liter penicillin, and $100 \mathrm{mg} /$ liter streptomycin (Gibco), 0.1 mM MEM nonessential amino acid (Gibco), and $10 \mathrm{mM} \quad N$-2-hydroxyethylpiperazine- $N^{\prime} 2$-ethanesulfonic acid (HEPES) (Gibco) buffer solution in a humid atmosphere at $37^{\circ} \mathrm{C}$ and $5 \% \mathrm{CO}_{2}$.

On day 7 after plating, the media were changed from media containing serum to media without serum (DTS). DTS medium was DMEM (Gibco) supplemented with $5 \mathrm{mg} /$ liter iron-saturated human transferrin (Sigma, St. Louis, MO) and $5 \mu \mathrm{g}$ /liter selenous acid $\left(\mathrm{Na}_{2} \mathrm{SeO}_{3}\right.$; Collaborative Biomedical, Bedford, MA) but contained no serum (20). Caco-2 cells grow and differentiate normally in DTS medium (20). Experimental protocols were initiated on day 14, when cells were confluent.

Protocol of Incubation with Butyrate and Stimulation with $I L-1 \beta$ or Lipopolysaccharide

IL-8 AND MCP-1 SECRETION BY INTESTINAL EPITHELIAL CELLS IN DTS MEDIA CONTAINING BOTH SODIUM BUTYRATE AND/OR LIPOPOLYSACCHARIDE OR IL- $1 \beta$. Caco-2 cells were incubated with varying concentrations of butyrate $(0-20 \mathrm{mM})$ in DTS media without serum for $48 \mathrm{hr}$. No changes in the $\mathrm{pH}$ of the media were observed with the addition of butyrate. The epithelial cells were stimulated with $100 \mu \mathrm{g} / \mathrm{ml}$ lipopolysaccharide (LPS) (from Escherichia coli serotype 055:85, Sigma) or 1 $\mathrm{ng} / \mathrm{ml}$ IL-1 $\beta$ (RED Systems, Minneapolis, MN) during the last $24 \mathrm{hr}$. Experiments were also performed to examine IL-8 and MCP-1 mRNA accumulation within Caco-2 cells incubated with sodium butyrate $(0-5 \mathrm{mM})$ for $24 \mathrm{hr}$ and subsequently stimulated for $2 \mathrm{hr}$ with $1 \mathrm{ng} / \mathrm{ml} \mathrm{IL}-1 \beta$ or $100 \mu \mathrm{g} / \mathrm{ml}$ LPS.

To determine whether butyrate's action on histone acetylation and MCP-l production was reversible, butyrate was removed from the culture media after $24 \mathrm{hr}$ incubation and replaced with fresh serum-free media. Histone acetylation and MCP-1 production in Caco- 2 cells were determined at 0,2 , and 6 days after the removal of 
butyrate. At these times IL- $1 \beta$ was given and MCP-1 secretion was measured $24 \mathrm{hr}$ later.

\section{Assay of IL-8 and MCP-1 Secretion and $m R N A$} Accumulation

MEASUREMENT OF IL-8 AND MCP-1 SECRETION. IL-8 and MCP-1 levels were quantitated in cultured supernatants by enzyme linked immunosorbent assay (ELISA) for IL-8 and MCP-1 (Quantikine $^{\mathrm{TM}}$, R\&D Systems). The culture supernatants from Caco- 2 cells were collected, centrifuged at $800 \mathrm{rpm}$, and stored frozen at $-20^{\circ} \mathrm{C}$. The amount of IL-8 was quantified within each supernatant in duplicates. The maximum variation between duplicates was $2 \%$. Colorimetric results were read on a Titertek Multiscan II 96well plate reader at a wavelength of $450 \mathrm{~nm}$. Quantitation of IL-8 and MCP-1 was determined using a standard calibration curve for each chemokine.

MEASUREMENT OF TOTAL CACO-2 CELL PROTEIN. The total protein content of cell monolayers was measured to express chemokine production per unit weight of cellular material. Deionized water was placed into wells containing adherent Caco- 2 cells to detach the cells. They were immediately sonicated with an ultrasonic cell disrupter (Kontes microultrasonic cell disrupter, Vineland, NJ) to release cellular proteins. Protein was measured with the Bicinchonic Acid Protein Assay (Pierce BCA Protein Assay, Rockford, IL). Colorimetric results were read on a DU-70 spectrophotometer (Beckman Instrument, Wakefield, MA) at a wavelength of $562 \mathrm{~nm}$ and converted into protein concentration using an albumin standard calibration curve. The protein content within each well was measured in duplicates with an experimental variation of $<5 \%$.

CACO-2 CELL MRNA COLLECTION. Caco-2 cells were cultured with sodium butyrate $(0-5 \mathrm{mM})$ for $24 \mathrm{hr}$ followed by IL- $1 \beta$ for $2 \mathrm{hr}$. Caco- 2 cells were homogenized and the RNA extracted, precipitated, washed, and collected according to the manufacturer's recommendations as described in the procedures for RNA isolation using the Trizol Reagent (Gibco).

RNA TRANSFER BLOT ANALYSIS OF CACO-2 CELL mRNA. For RNA transfer blot analysis, $30 \mu \mathrm{g}$ of purified total RNA from each well was electrophoresed in a $2 \%$ agarose gel containing $1.8 \%$ formaldehyde
(Mallinckrodt, Paris, KY) and 20\% 3-[N-morpholino]propanesulfonic acid (MOPS) (Sigma) and transferred to Gene Screen Plus ${ }^{\mathrm{TM}}$ membranes (Dupont/NEN, Boston, MA) by capillary action. The membranes were then baked, prehybridized, hybridized, with labeled IL-8 cDNA (a gift from Dr. Joost Oppenheim) or MCP-1 cDNA (12). Blots were washed in $0.5 \times$ SSC and $0.5 \%$ SDS (Bio-Rad Laboratories, Hercules, CA) at $65^{\circ} \mathrm{C}$. Washed blots were autoradiographed between intensifying screens at $-70^{\circ} \mathrm{C}(13)$.

HISTONE EXTRACTION AND SEPARATION. Histones were extracted from Caco- 2 cells according to Cousens and Alberts (21). Cells were plated at $5 \times 10^{4}$ cells $/ \mathrm{cm}^{2}$ in $75-\mathrm{cm}^{2}$ flasks for 14 days. After $24 \mathrm{hr}$ incubation with either butyrate $(5$ $\mathrm{mM})$, trichostatin-A (10 $\mu \mathrm{M})$, or media alone, cells were removed and the nuclear protein harvested by centrifuging in MLB buffer $160 \mathrm{mM}$ $\mathrm{KCl} / 15 \mathrm{mM} \mathrm{NaCl} / 3 \mathrm{mM} \mathrm{MgCl}_{2} / 15 \mathrm{mM}$ piperazine- $N / N^{\prime}$ bis $\{2$ ethanesulfonic acid\}, $\mathrm{pH}$ $6.5 / 0.1 \%$ Nonidet P-40/0.5 mM phenyl methyl sulfonyl fluoride/l $\mathrm{mM}$ tetrathionate). The nuclear pellet was suspended in $\mathrm{H}_{2} \mathrm{SO}_{4}$ to a final concentration of $0.2 \mathrm{M}$ for $2 \mathrm{hr}$. The suspension was centrifuged and the supernatants containing the histones removed. The dissolved histones were precipitated with alcohol at $-20^{\circ} \mathrm{C}$. The precipitant was suspended in water, quantified, and $50 \mu \mathrm{g}$ of each sample loaded onto a triton $\mathrm{X}$-acetic acid-urea gel for histone separation. Gels were stained with Coumassie blue and destained in methanol and acetic acid. The position of the histone- 4 was identified with a histone-4 marker (Boehringer Mannheim). In addition to butyrate, the effect of other short-chain fatty acids and that of trichostatin-A, a histone deacetylase inhibitor (22), on histone acetylation were determined. Each of these reagents was given for $24 \mathrm{hr}$ before adding IL-1 $\beta$ to the media.

\section{Statistics}

Differences between sets of wells were examined by analysis of variance, using the Gabriel test for multiple comparisons. Results with a probability of $<0.05$ were considered significant.

\section{Results}

Butyrate Differentially Regulates Secretion of IL-8 and MCP-1 from Caco-2 Cells

The intestinal epithelial cell line Caco-2 does not normally secrete IL-8, but it expresses MCP-1 


\section{Results}

Butyrate Differentially Regulates Secretion of $I L-8$ and MCP-1 from Caco-2 Cells

The intestinal epithelial cell line Caco-2 does not normally secrete IL-8, but it expresses MCP-1 (Fig. 1). This reflects the secretion of chemokines from epithelial cells in vivo (12). Butyrate increased the secretion of IL- 8 in a dose-dependent manner. However, butyrate decreased the production of MCP-1 (Fig. 1). Thus, butyrate, a bacterial fermentation product, regulated the expression of IL-8 and MCP-1 by intestinal epithelial cells in different directions. In the absence of butyrate, LPS had no effect on IL-8 and MCP-1 secretion by Caco-2 cells (Fig. 2). However, with butyrate, LPS induced the secretion of IL-8, as previously described (13). In cells stimulated with LPS, butyrate also increased IL-8 and decreased MCP-1 secretion (Fig. 2).

IL $-1 \beta$ is a proinflammatory cytokine synthesized and secreted by macrophages in the intestinal mucosa during inflammation. IL- $1 \boldsymbol{\beta}$ activated intestinal epithelial cells to secrete IL-8 and MCP-1 in increased amounts (Fig. 3). Again, butyrate increased IL-8 secretion and decreased MCP-1 secretion. Butyrate had a marked effect on chemokine secretion because IL- $1 \beta$ produced a strong stimulatory response on both chemokines. The differential regulation of butyrate on IL-8 and MCP-1, therefore, did not depend on whether cells were stimulated by LPS or IL-1 $\beta$ or had received no proinflammatory stimuli.

\section{Butyrate Differentially Alters $I L-8$ and MCP-1 mRNA Accumulation in IL-1 $\beta$-Stimulated Caco-2 Cells}

To exclude the possibility that the differential effects of butyrate acted on the translation of chemokine mRNA or on a post-translational mechanism (such as chemokine secretion), we examined MCP-1 and IL-8 mRNA accumulation (Fig. 4). RNA was collected after $24 \mathrm{hr}$ of butyrate $(0-5 \mathrm{mM})$ followed by $2 \mathrm{hr}$ of IL-1 $\beta$. Chemokine mRNA accumulation mirrored the changes seen in chemokine secretion: IL-8 mRNA was increased by butyrate, whereas MCP-1 mRNA was decreased. Butyrate, therefore, differentially regulated the pattern of $\mathrm{IL}-8$ and MCP-1 mRNA accumulation in intestinal epithelial (Caco-2) cells.

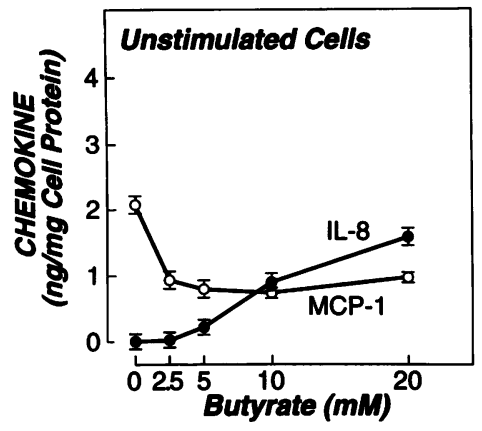

Fig. 1. Butyrate switches the secretion of IL-8 and MCP-1 by intestinal epithelial (Caco-2) cells. Butyrate was given 14 days after plating and supernatants were collected after $48 \mathrm{hr}$. IL-8 and MCP-1 were measured by ELISA. Caco- 2 cells constitutively secrete MCP-1 but not IL-8. In cells incubated with butyrate, there is an increase in IL-8 secretion $(p<0.0001)$ while secretion of MCP-1 is decreased $(p<0.001)$. Bars represent standard deviations of three wells for each point. The data are representative of five experiments.

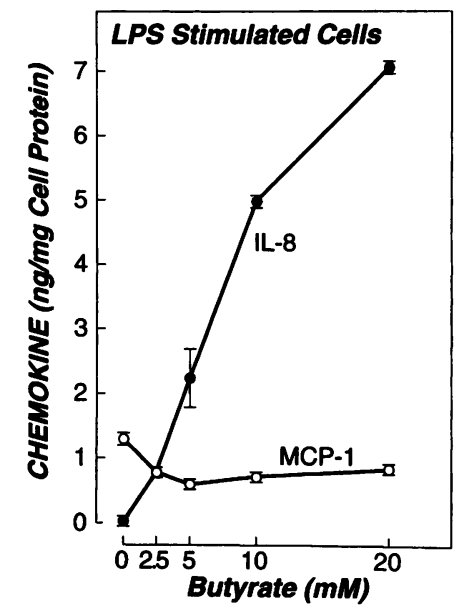

Fig. 2. Butyrate regulated chemokine secretion in epithelial cells stimulated with LPS. Cells received butyrate 14 days after plating. After butyrate had been added for $24 \mathrm{hr}$, LPS $(100 \mu \mathrm{g} / \mathrm{ml})$ was added for a further $24 \mathrm{hr}$. LPS alone had no effect on the secretion of chemokines in Caco- 2 cells. However, in the presence of butyrate, IL-8 secretion was markedly increased $(p<0.0001)$ whereas MCP-1 secretion decreased $(p<0.002)$. Bars represent standard deviations of three different wells for each point. The data are representative of five experiments.

Trichostatin-A Induces Histone Acetylation in Caco-2 Cells and Increases IL-8 Secretion While Decreasing MCP-1 Secretion

Butyrate increased both the acetylation of histones and the secretion of IL- 8 by epithelial cells when stimulated with $I L-1 \beta$ (Fig. 5). Butyrate 


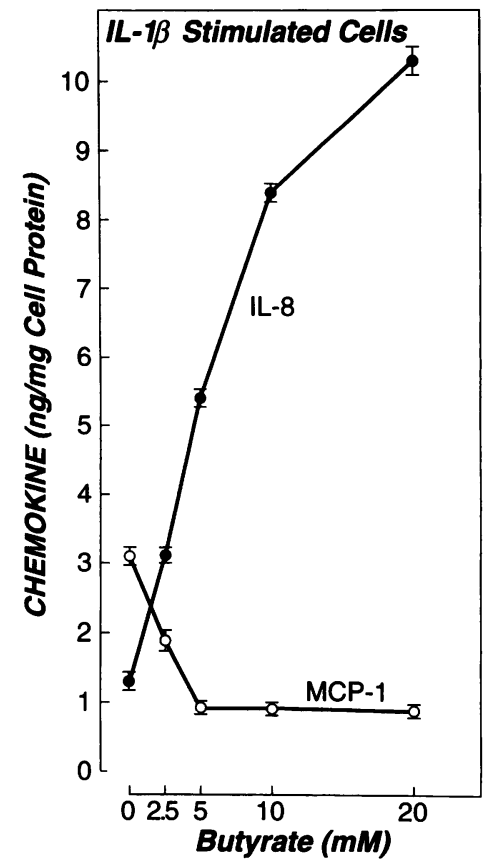

Fig. 3. Effect of IL-1 $\beta$ and butyrate on IL-8 and MCP-1 secretion by Caco-2 cells. IL- $1 \beta$ alone stimulated the secretion of both IL- 8 and MCP-1. Butyrate differentially regulates the pattern of chemokine secretion in IL-1 $\beta$-stimulated cells. IL-8 secretion was increased $(p<0.0001)$ whereas MCP-1 secretion was decreased $(p<0.0001)$. Bars represent standard deviations of three different wells for each point. The data are representative of five experiments.

down-regulated MCP-1 production at the same time (Fig. 5). We hypothesized that butyrate acted on IL-8 and MCP-1 secretion through its ability to induce histone acetylation by inhibiting histone deacetylase. To determine if histone acetylation increased IL-8 secretion and decreased MCP-1 production, we inhibited histone deacetylase by a separate mechanism. Trichostatin-A is a specific inhibitor of histone deacetylase and is 1000 -fold more potent than butyrate. Addition of trichostatin-A to Caco-2 cells increased the acetylation of histones (Fig. 5). At the concentrations required to cause the degree of histone acetylation comparable to that of butyrate, trichostatin-A increased the secretion of IL- 8 and decreased that of MCP- 1 in cells stimulated with IL- $1 \beta$. Therefore, the differential effects of butyrate on the regulation of IL- 8 and MCP-1 secretion can be explained by its action on histone acetylation.

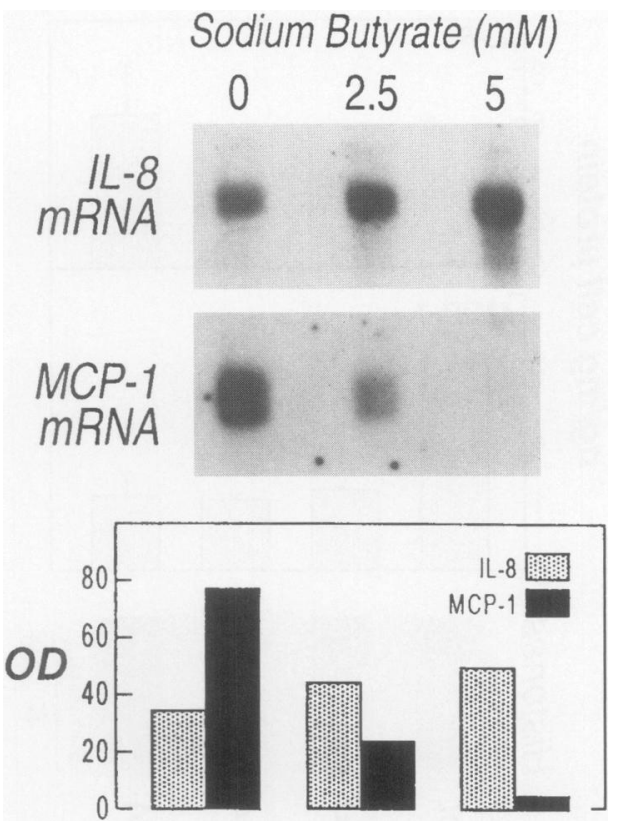

Fig. 4. Effect of butyrate and IL-1 $\beta$ on IL-8 and MCP-1 mRNA accumulation in Caco-2 cells. Caco-2 cells were preincubated with butyrate $(0,2.5,5 \mathrm{mM})$ for $24 \mathrm{hr}$ and then stimulated with $\mathrm{IL}-1 \beta(\mathrm{ng} / \mathrm{ml})$ for $2 \mathrm{hr}$. IL-8 mRNA (upper panel) was increased by butyrate, whereas MCP-1 mRNA was decreased. These observations were quantified using densitometry (lower panel). The data are representative of three experiments.

Histone Acetylation and Down-Regulation of MCP-1 Induced by Butyrate Are Both Reversible

Fourteen days after plating, Caco-2 cells were incubated with butyrate for $24 \mathrm{hr}$, washed, and the media replaced with fresh DTS media. IL- $1 \beta$ was added, in different arms of the experiment, on days 1,3 , and 7 after butyrate incubation. Histone acetylation was also examined at these times. MCP-1 mRNA and MCP-1 secretion were examined at 2 and $24 \mathrm{hr}$, respectively, after IL$1 \beta$. As in earlier experiments, butyrate induced histone acetylation and down-regulated MCP-1 production in Caco-2 cells (Fig. 6). However, butyrate's effect on histone acetylation had disappeared by day 3, 2 days after its removal from the culture media. At this time, MCP-1 protein secretion and MCP-1 mRNA were no longer inhibited. On day 7 , stimulation with IL- $1 \beta$ also induced MCP-1. Thus, the effects of butyrate on MCP-1 expression and histone expression were completely reversible. 


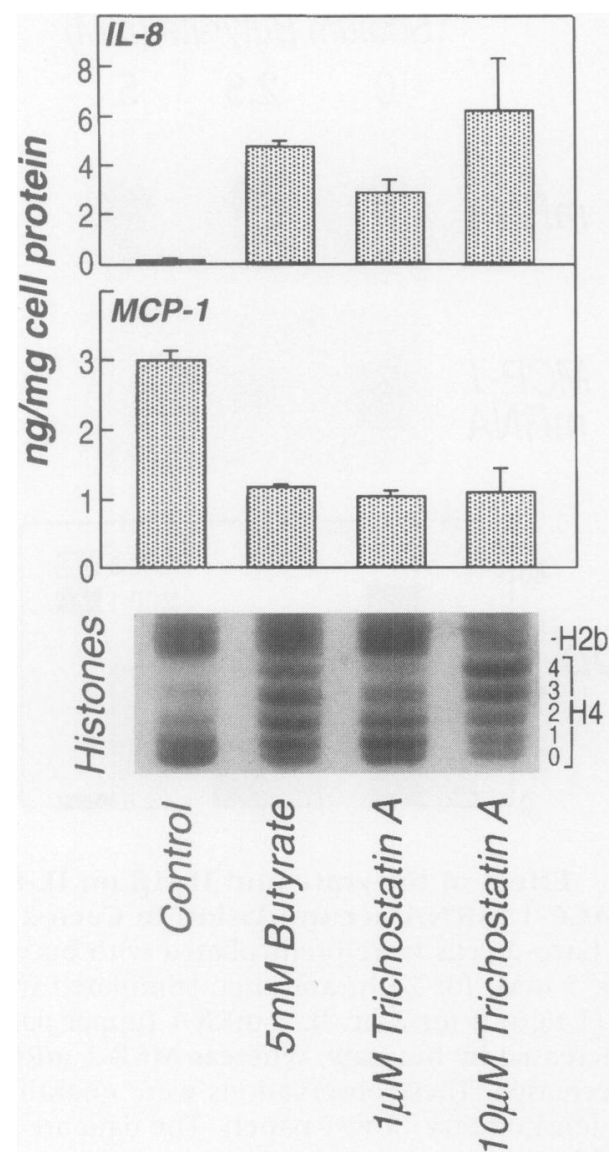

Fig. 5. Effect of butyrate and trichostatin- $A$ in the induction of histone acetylation and chemokine secretion by Caco-2 cells. Both butyrate and trichostatin-A increased the acetylation of histones. IL-8 secretion was simultaneously increased $(p<0.0001)$ and MCP-1 production decreased in Caco- 2 cells stimulated with IL- $1 \beta(p<0.001)$. Trichostatin-A, a specific histone deacetylase inhibitor, acted in a manner similar to that of butyrate when given at concentrations that produced a comparable change in histone acetylation. Bars represent standard deviations of three different wells for each point. The data are representative of three experiments.

hexanoate (C6) were added to Caco-2 cells for 24 hr. The relative effect of butyrate on histone acetylation was quantified by measuring the densitometry of the acetylated histone- 4 as a ratio of unacetylated histone- 4 in the sample (Fig. 7). The effect of each short-chain fatty acid on chemokine expression was simultaneously studied. Propionate, butyrate, and valerate altered the pattern of IL- 8 and MCP-1 secretion (Fig. 7). Moreover, they altered chemokine secretion according to the degree by which histones were acetylated (Fig. 7). There was no

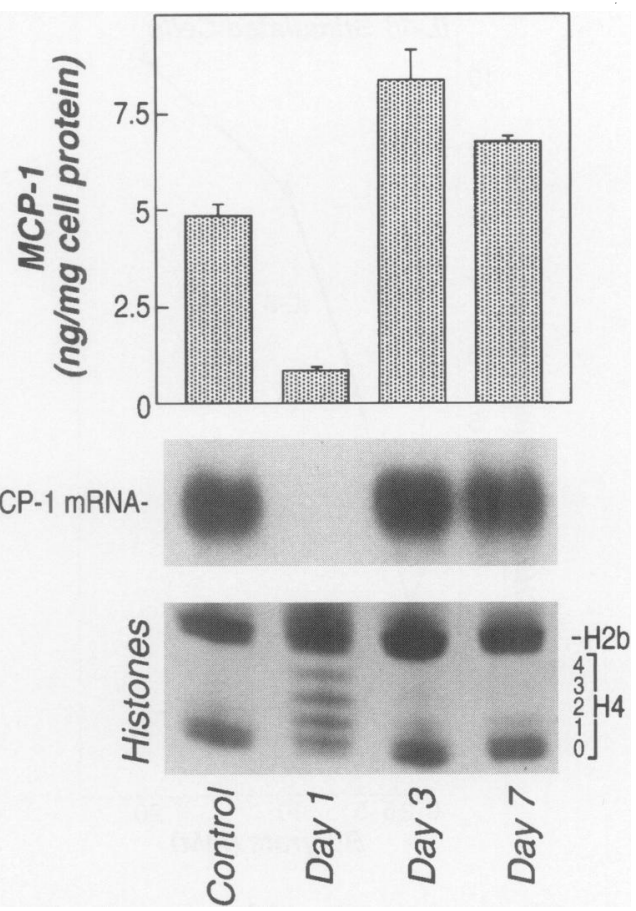

Fig. 6. The effects of butyrate on histone acetylation and MCP-1 inhibition were reversible. Cells were given butyrate for $24 \mathrm{hr} 14$ days after plating. Cells received IL- $1 \beta$ either immediately after butyrate had been removed from the culture media (day 1), or 2 days (day 3) and 6 days later (day 7). MCP-1 mRNA and MCP-1 secretion were measured $2 \mathrm{hr}$ and $24 \mathrm{hr}$ after IL-1 $\beta$. Results were compared with cells that received no butyrate (control). Histone acetylation was examined at each time point at which IL- $1 \beta$ was given. Butyrate inhibited the expression of MCP-1, as previously shown. However, this effect was reversed by day 3, 2 days after butyrate had been removed. This change was concurrent with the loss of acetylation of histone-4. The effects of butyrate on histone acetylation and MCP-1 production in Caco- 2 cells were, therefore, reversible. Bars represent standard deviations of three different wells for each point. The data are representative of three experiments.

relation between the energy content of any particular short-chain fatty acid and its effects on chemokine expression.

\section{Discussion}

The intestinal lumen contains a multitude of antigenic and proinflammatory agents derived from the diet and from the microflora. Cells of the mucosal immune system play a crucial role in initiating, activating, and perpetuating inflammatory and immune mechanisms. The epithe- 


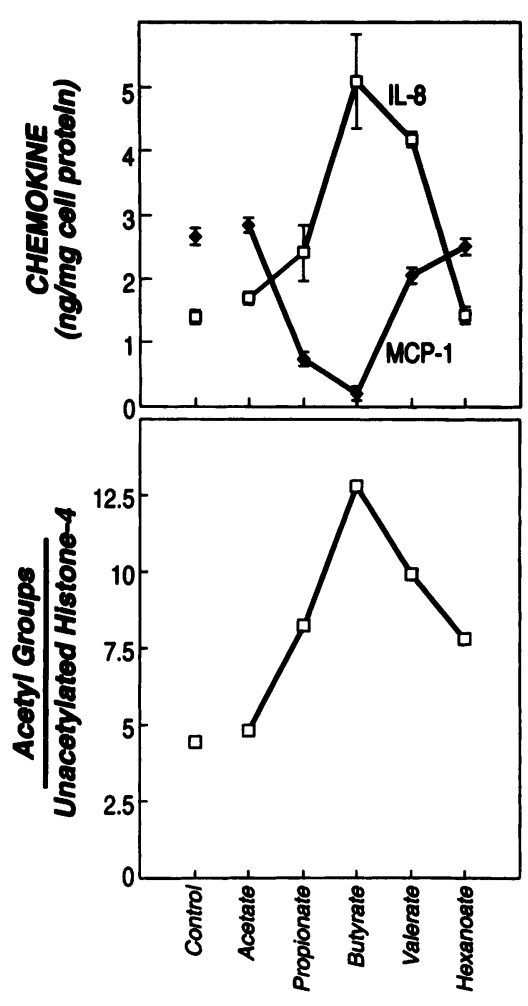

Fig. 7. Short-chain fatty acids of different chain lengths (C2-C6) alter IL-8 and MCP-1 production according to their effects on histone acetylation. Here $5 \mathrm{mM}$ each of acetate (C2), propionate (C3), butyrate (C4), valerate (C5), and hexanoate (C6) were added to Caco-2 cells for 24 $\mathrm{hr}$. IL-1 $\beta$ was then given for a further $24 \mathrm{hr}$. Acetate and hexanoate had little effect on acetylation and on chemokine expression ( $p$, not significant). Valerate and propionate altered both chemokine secretion $(p$ $<0.01$ ) and histone acetylation, but the effects were less than those of butyrate. Bars represent standard deviations of three different wells for each point. The data are representative of three experiments.

lium, therefore, serves as an important barrier separating the luminal contents from immunocytes (1). However, an impenetrable barrier would inhibit the mucosal immune system from surveying the constituents of the lumen. $M$ cells, which allow the controlled passage of antigens and microbial agents, permit sampling of the intestinal lumen (23). Release of cytokines by the epithelium in response to luminal factors represents an additional process by which intestinal contents can be surveyed (24). Although the microflora alter the expression of enzymes that regulate epithelial cell surface molecules (25), little attention has been paid to the effect of normal luminal bacteria on cytokine expression. It seems likely that the intestine responds to variations in resident bacteria by subtle changes in its immunoregulation. Such changes would be smaller than inflammatory responses to invasive pathogens.

In our experiments, we examined the effects of the bacterial product butyrate on IL-8 and MCP-1 production in the cultured intestinal epithelial cell line Caco-2. Butyrate increased the secretion of IL- 8 by Caco- 2 cells and decreased the production of MCP-1 (Fig. 1) in a dose-dependent fashion. Moreover, when the cells were subsequently stimulated with IL- $1 \beta$, a proinflammatory cytokine secreted by macrophages in response to inflammatory stimuli, a marked differential response of IL-8 and MCP-1 was observed (Fig. 3). Similar patterns were observed in the accumulation of mRNA for both of these chemokines (Fig. 4). These observations were not restricted to Caco- 2 cells. In $\mathrm{H} 4$ cells, a nonmalignant human intestinal epithelial cell line derived from the fetus, butyrate inhibited MCP-1 (R.D. Fusunyan et al., unpublished data) and increased IL-8 secretion (13) in cells stimulated with IL-1 $\beta$.

In our experiments (Fig. 1), the changes in IL-8 and MCP-1 were small in the absence of a proinflammatory stimulus. This is consistent with the observation that short-chain fatty acids do not normally induce neutrophil in vivo [except at high concentrations (26) where, in mice, inflammatory changes were observed]. On the other hand, the increase in IL-8 production in cells (Fig. 3) receiving a proinflammatory stimulus was large in the presence of butyrate. Thus, only in the presence of inflammation would butyrate markedly alter epithelial cell IL-8 expression. The increased butyrate concentrations reported in both Crohn's colitis (9) and necrotizing enterocolitis (11) may therefore contribute to the inflammatory changes.

We examined IL-8 secretion into the lumen in normal subjects with no evidence of intestinal inflammation (27). Rectal dialysates were collected by inserting bags made from dialysis tubing for $4 \mathrm{hr}$. Low levels of IL-8 were detected in the dialysate. However, similar experiments performed on patients with colitis showed greater IL-8 secretion. The IL-8 collected induced neutrophil activation. Short-chain fatty acid enemas have been used therapeutically in patients with diversion colitis (28) and distal ulcerative colitis with limited success (29), but they have not been beneficial to patients with Crohn's disease. Instead, elemental diets that are low in fiber (an important substrate for short-chain fatty acids) 
trophil activation. Short-chain fatty acid enemas have been used therapeutically in patients with diversion colitis (28) and distal ulcerative colitis with limited success (29), but they have not been beneficial to patients with Crohn's disease. Instead, elemental diets that are low in fiber (an important substrate for short-chain fatty acids) decrease Crohn's disease activity (30) and reverse growth retardation in children (31). This observation is consistent with the assertion that butyrate may enhance inflammation in Crohn's disease. Furthermore, the benefits of short-chain fatty acids in ulcerative colitis do not conflict with the data presented in this report. Butyrate is a nutrient of the colonic epithelial cell; it reduces epithelial permeability (32) and facilitates salt and water absorption in the colon. Ulcerative colitis is characterized by changes in epithelial cell morphology and often loss of surface epithelial cells. At early stages of the disease, when injury to epithelial cells is greatest, the benefit of butyrate is statistically significant (33).

The effects of butyrate on cultured epithelial cells were reversible (Fig. 6), both in terms of histone acetylation and their effects on the inhibition of MCP-1. The stimulation of IL- 8 by butyrate was also reversed (R.D. Fusunyan et al., unpublished data). These data support the assertion that the changes observed with short-chain fatty acids were an active response, and not the result of cell damage. Furthermore, the distinct direction in which the two chemokines alter makes apoptosis (34) or other causes of cell death an unlikely trigger for these phenomena.

The switching of chemokines from IL-8 to MCP- 1 by butyrate was mimicked by trichostatin-A (Fig. 5). This compound has no chemical similarity to short-chain fatty acids. It is 1000fold more potent than butyrate in inhibiting histone deacetylase (22). At the concentrations at which trichostatin-A induced the same effect on histone acetylation as butyrate, it induced a similar response in chemokine regulation (Fig. 5). In addition, other short-chain fatty acids varied the expression of chemokines according to their ability to induce histone acetylation (Fig. 7). We also investigated the effect of glutamine, another intestinal epithelial cell nutrient. Glutamine had no effect on IL- 8 production by Caco- 2 cells. The effects of short-chain fatty acids, therefore, were specific and not related to the delivery of energy to the epithelial cell. Furthermore, IL- $1 \beta$ alone did not induce histone acetylation (unpublished data). These data, therefore, support the hypothesis that short-chain fatty acids switch chemo- kine expression through their effects on histone acetylation. Nevertheless, demonstrating that histone acetylation alters chemokine secretion does not exclude other mechanisms of gene regulation involving regulatory elements of chemokine promoters. Stability of RNA could, in theory, also be altered by butyrate; however, butyrate did not alter the stability of mRNA for another chemokine, macrophage inflammatory protein-2, in a rat intestinal epithelial cell line (35).

Evidence is accumulating that chromosomal proteins are important in regulating transcription (36). Recently, the involvement of histone tails in binding to DNA has been inferred from experiments in which histones have been thermally denatured (37). In vivo, changes in the charges of histones are normally the result of acetylation. The hydrogen atom in the free lysine group of the histones is normally substituted by an acetyl group. This reduces the net positive charge on the histone molecule, resulting indirectly in the destabilization of the chromatin structure (38).

The question arises as to how butyrate can have distinct effects on different genes. The variability of butyrate in increasing transcription in any particular gene can be explained by the proximity of the gene to a "scaffold attachment region" (39). Such regions, rich in AT sequences, form the basis by which DNA is bound to nonchromosomal structures in the nucleus. Studies on plasmids containing the IFN $\beta$ gene (40) linked to a scaffold attachment sequence showed that close proximity to such a sequence results in a much greater sensitivity of transcription to butyrate. In this case, adding scaffold attachment sequences to the DNA containing the IFN $\beta$ gene increased the enhancing effect from 2 -fold to 80 -fold. Inhibition of gene expression, however, cannot be explained by the involvement of scaffold attachment regions, and different mechanisms responsible for the down-regulation of MCP-1 must be inferred. It has been suggested that butyrate may inhibit genes whose promoters include a $\kappa B$ sequence (41), by up-regulating the inhibitor I $\kappa \mathrm{B}$. However, changes in I $\kappa \mathrm{B}$ cannot explain the distinct effects of butyrate on IL-8 and MCP-1 because the promoters of both genes contain a $\kappa \mathrm{B}$ element. Regulation through $N F \kappa B$ should, therefore, induce changes in expression in the same direction. IL- $1 \beta$, for example, acts through the $\kappa \mathrm{B}$ site; and both IL- 8 and MCP-1 are up-regulated by its actions (Figs. 1 and 3 ). It seems likely, therefore, that an as-yet unidentified inhibitor is up-regulated by butyrate and acts on the MCP-1 promoter. 
In conclusion, we have shown for the first time that butyrate switches the expression of chemokines by intestinal epithelial cells. Its effects are mediated through histone acetylation. We believe we have defined a mechanism in human intestinal epithelial cells by which resident bacteria may regulate inflammatory processes within the intestine.

\section{Acknowledgments}

This work was supported by grants DK47753, AI 43472, DK21474, DK40561, DK43351, DK08894, and DK02481 from the National Institutes of Health; the K.C. Irving Family Research Fellowship Fund; Lahey-Hitchcock Clinic Foundation; and the Hood Foundation. Dr. Ian Sanderson was also supported by the Crohn's and Colitis Foundation of America. The authors are grateful to Dr. David Schoenfeld for his advice with statistical analyses.

\section{References}

1. Sanderson IR, Walker WA. (1994) Mucosal barrier. In: Ogra PL, Mestecky J, Lamm ME, Strober W, McGhee JR, Bienenstock J (eds). Handbook of Mucosal Immunology, 2nd ed. Academic Press, San Diego, pp. 41-48.

2. Stadnyk AW. (1994) Cytokine production by epithelial cells. FASEB J. 8: 1041-1047.

3. Jung HC, Eckmann L, Yang SK, et al. (1995) A distinct array of proinflammatory cytokines is expressed in human colon epithelial cells in response to bacterial invasion. J. Clin. Invest. 95: 55-65.

4. McCormick BA, Hofman PI, Kim J, Carnes DK, Miller SI, Madara JL. (1995) Surface attachment of salmonella typhimurium to intestinal epithelia imprints the subepithelial matrix with gradients chemotactic for neutrophils. J. Cell Biol. 131: 1599-1608.

5. Cummings JH. (1981) Short chain fatty acids in the human colon. Gut 22: 763-769.

6. Royall D, Wolever BM, Jeejeebhoy KN. (1990) Clinical significance of colonic fermentation. Am. J. Gastroenterol. 85: 1307-1312.

7. Midtvedt AC, Midtvedt T. (1992) Production of short chain fatty acids by the intestinal microflora during the first two years of human life. J. Pediatr. Gastroenterol. Nutr. 15: 395-403.

8. Kripke SA, Fox AD, Berman JM, Settle RG, Rombeau JL. (1989) Stimulation of intestinal mucosal growth and intracolonic infusion of short chain fatty acids. J. Parenter. Enter. Nutr. 13: 109-1 16.

9. Treem WR, Ahsan N, Shoup M, Hyams J. (1994) Fecal short chain fatty acids in children with in- flammatory bowel disease. J. Pediatr. Gastroenterol. Nutr. 18: 159-164.

10. Lloyd DR, Brown JD, Brown GA, Booth IW. (1992) Elevated short chain fatty acid concentrations in anaerobic bowel contamination. Acta Paediatr. 81: 51-56.

11. Dabard J, Hudault S, Saby MA, Gabilan JC, Szylit O, Raibaud P. (1987) Production of butyric acid in human premature baby suffering from necrotizing enterocolitis. Proceedings of the 9th International Symposium on Gnotobiology, Versailles, pp. 90-95.

12. Reinecker HC, Loh EY, Ringler DJ, Mehta A, Rombeau JL, MacDermott RP. (1995) Monocytechemoattractant protein 1 gene expression in intestinal epithelial cells and inflammatory bowel disease mucosa. Gastroenterology 108: 40-50.

13. Fusunyan RD, Quinn JJ, Ohno Y, MacDermott RP, Sanderson IR. (1998) Butyrate enhances interleukin- 8 secretion by intestinal epithelial cells in response to interleukin- $1 \beta$ and lipopolysaccharide. Pediatr. Res. 43: 84-90.

14. Norton VG, Imai BS, Yau P, Bradbury EM. (1989) Histone acetylation reduces nucleosome core particular linking number change. Cell 57: 449-457.

15. Bauer WR, Hayes JJ, White JH, Wolfe AP. (1994) Nucleosome structural changes due to acetylation. J. Mol. Biol. 236: 685-690.

16. Lutter LC, Judis L, Paretti RF. (1992) Effects of histone acetylation on chromatin topology in vivo. Mol. Cell. Biol. 12: 5004-5014.

17. Hebbes, TR, Thorne AW, Crane-Robinson C. (1988) A direct link between core histone acetylation and transcriptionally active chromatin. EMBO J. 7: 1395-1402.

18. Hebbes TR, Clayton AL, Thorne AW, Crane-Robinson C. (1994) Core histone acetylation co-maps with generalized DnaseI sensitivity in the chicken $\beta$-globin chromosomal domain. EMBO J. 13: 1823-1830.

19. Pinto M, Robine-Leon S, Appay MD, et al. (1983) Enterocyte-like differentiation and polarization of the human colon carcinoma cell line Caco-2 in culture. Biol. Cell 47: 323-330.

20. Oguchi S, Walker WA, Sanderson IR. (1994) Profile of IGF-binding proteins secreted by intestinal epithelial cells change with differentiation. Am. J. Physiol. 267: G843-G850.

21. Cousens LS, Alberts BM. (1982) Accessibility of newly synthesized chromatin to histone acetylase. J. Biol. Chem. 257: 3945-3949.

22. Yoshida M, Kijima M, Akita M, Beppu T. (1990) Potent and specific inhibition of mammalian histone deacetylase both in vivo and in vitro by trichostatin A. J. Biol. Chem. 265: 1714-1719.

23. Sanderson IR, Walker WA. (1993) Uptake and transport of macromolecules by the intestine: possible role in clinical disorders (an update). Gastroenterology 104: 622-639.

24. Sanderson IR. (1997) Diet and gene expression in 
ship D, MacDermott RP, Sanderson IR. (1999) Increased interleukin-8 (IL-8) in rectal dialysate from patients with ulcerative colitis: Evidence for a biological role for IL-8 in inflammation of the colon. Am. J. Gastroenterol. 94: 704-712.

28. Harig JM, Soergel KH, Komorowski RA, Wood CM. (1989) Treatment of diversion colitis with short chain-fatty acid irrigation. N. Engl. J. Med. 320: 23-28.

29. Sanderson IR. (1997) Diet and gut inflammation. Curr. Opin. Gastroenterol. 13: 518-524.

30. O'Morain C, Segal AW, Levi AJ. (1982) Elemental diet as primary treatment of acute Crohn's disease: A controlled trial. $B M J$ 288: 1859-1862.

31. Sanderson IR, Udeen S, Davies PSW, Savage MO, Walker-Smith JA. (1987) Remission induced by an elemental diet in small bowel Crohn's disease. Arch. Dis. Child 62: 123-127.

32. Vernia P, Cittadini M, Caprilli R, Torsoli A. (1995) Topical treatment of refractory distal ulcerative colitis with 5-ASA and sodium butyrate. Dig. Dis. Sci. 40: 305-307.

33. Breuer RI, Soergel KH, Lashner BA, et al. (1997) Short chain fatty acid rectal irrigation for leftsided ulcerative colitis: A randomised placebo trial. Gut 40: 485-491.

34. Janson W, Brandner G, Siegel J. (1997) Butyrate modulates DNA-damage-induced $\mathrm{p} 53$ response by induction of p53-independent differentiation and apoptosis. Oncogene 15: 1395-1406.
35. Ohno Y, Lee J, Fusunyan RD, MacDermott RP, Sanderson IR. (1997) Macrophage inflammatory protein-2: Chromosomal regulation in rat small intestinal epithelial cells. Proc. Natl. Acad. Sci. U.S.A. 94: 10279-10284.

36. Nowak R. (1995) Molecular machines may aid gene expression. Science 270: 1589-1590.

37. Hong L, Schroth GP, Matthews HR, Yau P, Bradbury EM. (1993) Studies of the DNA binding properties of histone $\mathrm{H} 4$ amino terminus. Thermal denaturation studies reveal that acetylation markedly reduces the binding constant of the $\mathrm{H} 4$ "tail" to DNA. J. Biol. Chem. 268: 305-314.

38. Luger K, Mader AW, Richmond RK, Sargent DF, Richmond TJ. (1997) Crystal structure of the nucleosome core particle at $2.8 \AA$ resolution. Nature 389: 251-260.

39. Klehr D, Maass K, Bode J. (1991) Scaffold-attached regions from the human interferon beta domain can be used to enhance the stable expression of genes under the control of various promoters. Biochemistry 30: 1264-1270.

40. Klehr D, Schlake T, Maass K, Bode J. (1992) Scaffold-attached regions (SAR elements) mediate transcriptional effects due to butyrate. Biochemistry 31: 3222-3229.

41. Wu GD, Huang N, Wen XM, Yang H. (1997) Induction of I $\kappa$ B-beta expression by sodium butyrate inhibits transcriptional activation of the interleukin-8 gene. Gastroenterology 112: A1121. 